\title{
Synthesis of eunicellane-type bicycles embedding a 1,3-cyclohexadiene moiety
}

\author{
Alex Frichert ${ }^{1}$, Peter G. Jones ${ }^{2}$ and Thomas Lindel ${ }^{* 1, \S}$
}

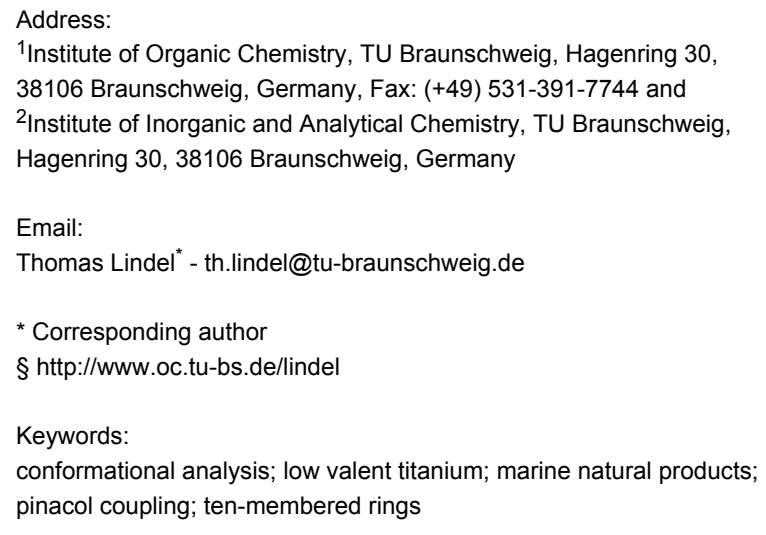

\begin{abstract}
The first synthesis of diterpenoid eunicellane skeletons incorporating a 1,3-cyclohexadiene moiety is presented. Key step is a lowvalent titanium-induced pinacol cyclization that proved to be perfectly diastereoselective. Determination of the relative configuration of the diol was aided by the conversion to the diastereomer by oxidation and reduction. Conformational analysis of some of the resulting diols obtained under McMurry conditions was complicated by the presence of several conformers of similar energy. The pinacol coupling appears to start at the ketone, as indicated by the selective reduction of non-cyclizing cyclohexane systems that were synthesized from limonene oxide. The title compounds and their synthetic precursors are prone to aromatization on contact with air oxygen. Attempted synthesis of cyclohexene-containing eunicellane bicycles by elimination of water from tertiary alkynyl carbinols afforded novel allene systems. Our study may be of help towards the total synthesis of solenopodin or klysimplexin derivatives.
\end{abstract}

\section{Introduction}

Eunicellane-type diterpenoids share an [8.4.0] bicyclic skeleton (1, Figure 1). In many cases, an additional oxygen bridge is present between positions 4 and 7, or 2 and 9, but there are also interesting eunicellanes without oxygen bridge, the majority of which has been isolated from marine corals. These comprise the solenopodins A-D (2, solenopodin D) from Solenopodium stechei [1], an unnamed eunicellane [2] and the klysimplexins Q and R (3, klysimplexin R) [3] from Eunicella labiata, cladieunicelline F from Cladiella sp. [4] and eunicellol A (4) from the soft coral Gersemia fruticose [5]. Magdalenic acid (5) was isolated from the plant Vellozia magdalenae [6]. Recently, prehydropyrene (6) was discovered as biosynthetic intermediate towards the diterpene hydropyrene from the Gram-positive bacterium Streptomyces clavuligerus [7]. The six- and ten- 
membered rings of eunicellane diterpenoids can be either cis or trans fused, and the ten-membered ring may contain $(Z)$ - or $(E)$ double bonds. None of them has been synthesized.<smiles>CC1CCCC(C)CC2C(C(C)C)CCC(C)C2CCC1</smiles>

1: eunicellane skeleton<smiles>CC1=CC[C@@H]2[C@@H](/C=C(\C)CC1)[C@@H](O)CC[C@@H]2C(C)C</smiles>

3: klysimplexin $\mathrm{R}$<smiles>C=C1CC[C@H](C(C)C)[C@H]2C=C3CCC=C(C(=O)O)C3C[C@H]12</smiles>

5: magdalenic acid<smiles>C=C1C[C@H](OC(C)=O)[C@@]2(C)C=C(C)CC[C@H](O)[C@]2(O)CCC1C(C)C</smiles>

2: solenopodin D

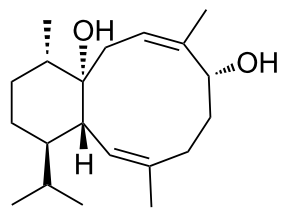

4: eunicellol $A$<smiles>C=C(C)[C@H]1CC[C@@H](C)[C@@H](C)/C=C2/CC/C=C(/C)CC[C@H]21</smiles>

6: prehydropyrene
Figure 1: Bicyclic eunicellane-type diterpenes.

A series of eunicellane-type bicycles containing a cyclohexene partial structure served as intermediates of the total syntheses of the sarcodictyins, the eleuthesides, and of eleutherobin $[8,9]$ The benzene-containing eunicellane derivative 7 (Figure 2) was obtained synthetically starting from the cembranoid sarcophytoxide from the soft coral Sarcophytum glaucum [10].

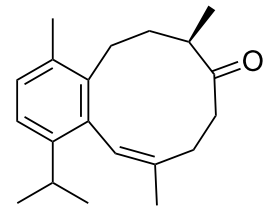

7

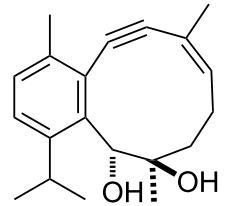

8
Figure 2: Synthetic eunicellane-type compounds with benzene partial structure.

We have shown that eunicellane $\mathbf{8}$ containing a benzene partial structure can be accessed efficiently via pinacol cyclization of a ketoaldehyde precursor [11]. However, compound $\mathbf{8}$ proved to be very resistant towards any attempt of partial hydrogenation of the benzene moiety. Systems embedding a cyclohexadiene ring should be more versatile, e.g., by allowing regio- and stereoselective hydrogenation and oxygenation towards partial structures present in compounds $\mathbf{2 - 6}$. In addition, we expected that the higher hydrogen count and the non-planarity of the envisaged 1,3-cyclohexadiene ring would allow the determination of the diastereoselectivity of the coupling step more precisely than in the case of aromatic $\mathbf{8}$ that exists as mixture of two conformers in $\mathrm{CDCl}_{3}$.

Thus, it was to be explored how open-ring cyclohexadiene precursors would be synthesized and behave under McMurry conditions, and how stable the resulting [8.4.0]bicycles would be. Normally, McMurry conditions lead to the formation of alkenes, but medium-sized ring 1,2-diols have also been obtained $\left(\mathrm{TiCl}_{4} / \mathrm{Zn}\right.$ [12-17] or $\mathrm{TiCl}_{3} / \mathrm{Zn}-\mathrm{Cu}$ [18-20]), often as mixture of diastereomers. The use of samarium diiodide to achieve the pinacol coupling was not advised, since we had observed that intially formed ketyl radicals would add to the alkyne moiety [11], even if there are examples, where this was not the case [21,22]. Access to partially unsaturated eunicellane systems could also be of interest for studies on biosynthesis and chemical interconversion $[7,10]$.

\section{Results and Discussion}

Dihydrocarvone 9 was converted to the enolate and quenched with ethyl cyanoformate in the presence of DMPU affording an inconsequential 5.6:1 mixture of diastereomers favoring $\mathbf{1 0}$ $\left({ }^{3} J_{3 \mathrm{H}-4 \mathrm{H}} 12.2 \mathrm{~Hz}\right.$ vs $4.8 \mathrm{~Hz}$, Scheme 1$)$. The cyclohexadiene system of $\mathbf{1 1}$ was formed after deprotonation of $\mathbf{1 0}$ (LiHMDS) and quenching with triflic anhydride. All compounds carrying the 1,3-cyclohexadiene motif were prone to aromatization and had to be protected from contact with air and higher temperatures. Removal of solvents was performed below $21^{\circ} \mathrm{C}$ and all compounds were stored under argon at $-18{ }^{\circ} \mathrm{C}$. Sonogashira coupling $\left(\mathrm{PdCl}_{2}\left(\mathrm{PPh}_{3}\right)_{2}\right)$ of dienol triflate 11 with alkyne 12 [11] provided $\mathrm{C}_{20}$ ester $\mathbf{1 3}$ in a good yield of $86 \%$. However, after hydrolysis of the 1,3-dioxolane moiety to ketoester 14 it proved to be impossible to induce any McMurry cyclization involving the two carbonyl groups of the system. Only starting material was isolated. We had hoped that the ester might participate in the cyclization, since there is precedence of accessing medium-sized ring ethyl vinyl ethers when employing $\mathrm{TiCl}_{3} /$ $\mathrm{LiAlH}_{4} / \mathrm{NEt}_{3}$ in DME instead of $\mathrm{TiCl}_{4} / \mathrm{Zn} /$ pyridine [23].

Direct reduction of ester $\mathbf{1 4}$ to the aldehyde proved to be surprisingly difficult with either DIBAL-H or $\mathrm{LiAlH}_{4}$, when the alkynyl side chain was in place. Thus, we reduced the ester function of dienol triflate $\mathbf{1 1}$ to the alcohol (DIBAL-H, DCM, $-78{ }^{\circ} \mathrm{C}$ ), followed by oxidation to aldehyde 15 (IBX, Scheme 2). Fortunately, the cyclohexadiene moiety survived the 
<smiles>CC1=CCC(C(C)C)CC1=O</smiles>

9

LiHMDS ( 1.0 equiv), $\mathrm{Tf}_{2} \mathrm{O}$ (1.2 equiv) THF, $-78^{\circ} \mathrm{C}$

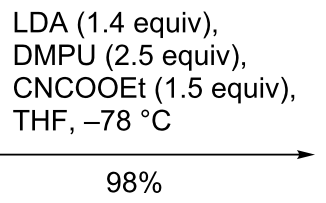

DMPU ( 2.5 equiv)

CNCOOEt (1.5 equiv),

$98 \%$ dr 5.6

10<smiles>CCOC(=O)C1=C(OCC)C(C)=CCC1C(C)C</smiles>

11

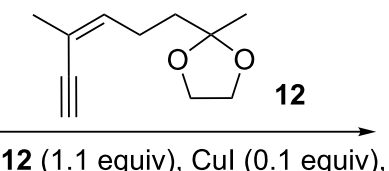

$\mathrm{PdCl}_{2}\left(\mathrm{PPh}_{3}\right)_{2}$ (0.1 equiv),

$\mathrm{Et}_{3} \mathrm{~N}, 0{ }^{\circ} \mathrm{C}$ to $\mathrm{rt}$<smiles>[M]C1COC(C)(CC/C=C(/C)C#CC2=C(C(=O)OCC)[C@H](C(C)C)CC=C2C)O1</smiles><smiles>CCOC(=O)C1=C(C#C/C(C)=C\CCC(C)=O)C(C)=CC[C@H]1C(C)C</smiles>

14

Scheme 1: Access to ketoester 14 that did not cyclize to the ethyl vinyl ether under McMurry conditions.

oxidation conditions, which was not the case when using PCC or $\mathrm{MnO}_{2}$. Subsequent Sonogashira coupling to $\mathbf{1 6}$ and deprotection to $\mathbf{1 7}$ worked satisfyingly. As in the case of a benzene partial structure (8), it was a diol that was formed from 17 under McMurry conditions (20 equiv $\mathrm{TiCl}_{4}, 40$ equiv $\mathrm{Zn}$, THF, rt). No alkene was detected.

McMurry-type pinacol cyclizations have shown varying degrees of diastereoselectivity, which means that every single example has to be explored independently. The assignment of the configuration and preferred conformation of product 18 was conducted on the basis of NOESY NMR experiments. Our analysis was aided by the observation that the 2-epimer 19 was accessible by oxidation of $\mathbf{1 8}$ to the acyloin (IBX, MeCN) and subsequent reduction $\left(\mathrm{LiAlH}_{4}, \mathrm{THF}\right.$, Scheme 2). Diastereomers 18 and 19 show distinct sets of NMR signals. The largest chemical shift differences are observed for the secondary carbinol group $\left(\delta_{2-\mathrm{H}} 5.18, \delta_{\mathrm{C} 2} 73.1\right.$ for $\mathbf{1 8}$ vs $\delta_{2-\mathrm{H}} 4.14, \delta_{\mathrm{C} 2} 87.2$ for $\left.\mathbf{1 9}\right)$. For diol 18, we observed key NOESY correlations between carbinol $2-\mathrm{H}(\delta 5.18)$ and one of the $\mathrm{C} 5$ methylene hydrogens $(\delta 2.37)$ and between $14-\mathrm{H}(\delta 2.43)$ and $3-\mathrm{CH}_{3}(\delta 1.20$, Figure 3$)$. For each of the four diastereomers with $14 R$ configuration we found one conformation (MM2) placing $2-\mathrm{H}$ and one $5-\mathrm{H}$ in proximity. Moreover, those conformations are within $10 \mathrm{~kJ} / \mathrm{mol}$ range of each other. However, only one of those conformations shows the required short distance between $14-\mathrm{H}$ and $3-\mathrm{CH}_{3}$, making the configuration $(2 R, 3 S, 14 R)$ probable for diastereomer 18. In the preferred conformation of 18, all non-sp ${ }^{3}-$

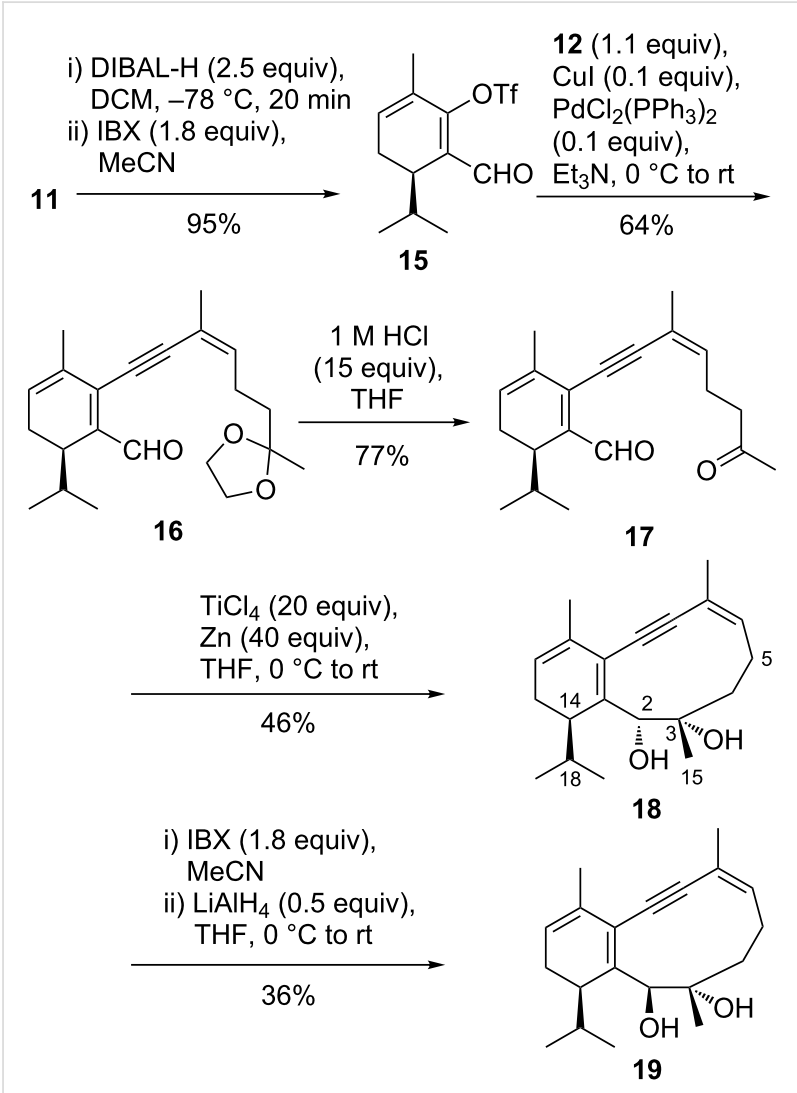

Scheme 2: Synthesis of the 1,3-cyclohexadiene-containing eunicellane-type [8.4.0]bicycle 18 by McMurry coupling to the diol, followed by two-step epimerization at $\mathrm{C} 2$. 
hybridized carbon atoms of the ring system and the adjacent atoms are located almost in plane, whereas the isopropyl group and ring carbons $\mathrm{C} 3$ and $\mathrm{C} 4$ are located on opposite sides of that plane. Since the oxidation/reduction sequence has affected the configuration at $\mathrm{C} 2$, diastereomer 19 is assigned the configuration $(2 S, 3 S, 14 R)$. For diastereomer 19, 2-H did not show a NOESY correlation to $5-\mathrm{H} \beta$, but instead a correlation to $14-\mathrm{H}$, to the isopropyl methine hydrogen, and to $3-\mathrm{CH}_{3}$. In addition, $3-\mathrm{CH}_{3}$ correlates with both methylene hydrogens at $\mathrm{C} 4$. We found only two conformers of the $(2 S, 3 S, 14 R)$ diastereomer that meet those constraints. One of them is shown in Figure 3.
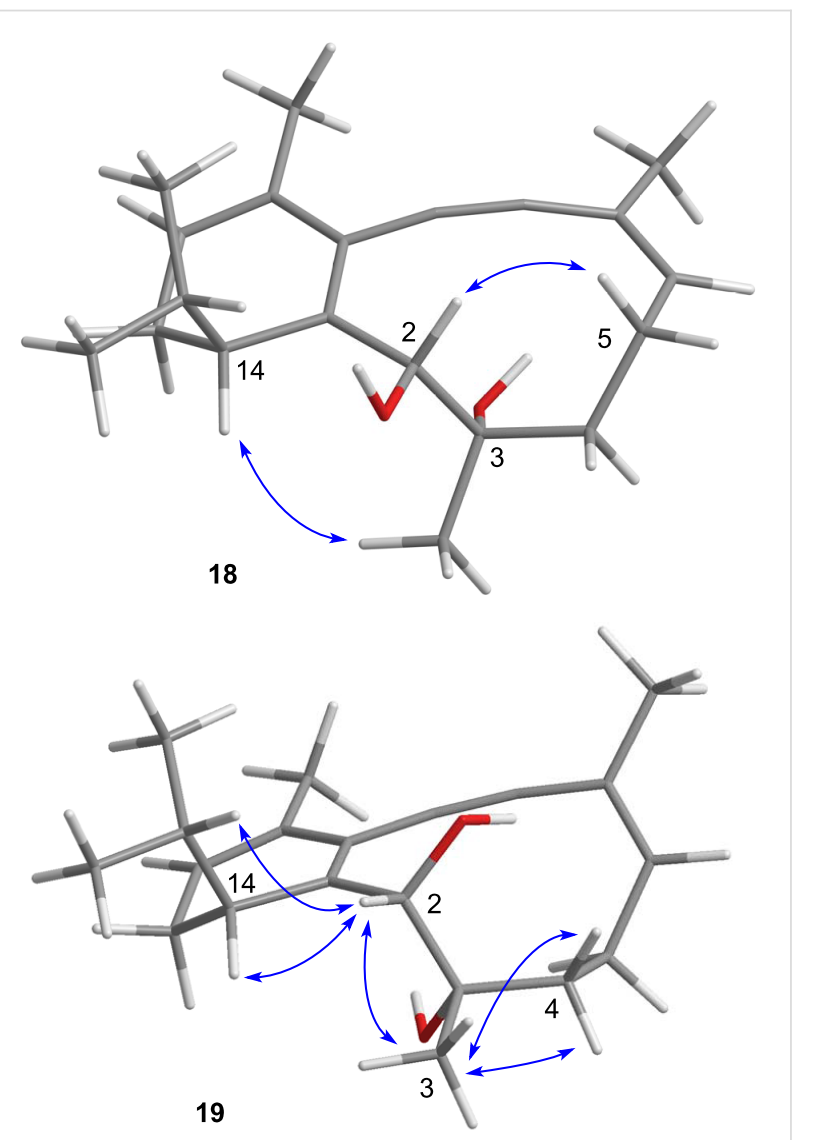

Figure 3: Preferred conformations of diastereomeric diols 18 and 19 including decisive NOESY correlations.

The transfer of the pinacol McMurry route to the formation of eunicellane-type bicycles with two $\mathrm{sp}^{3}$ centers as bridgeheads will not be straight-forward. This became clear on our attempts to cyclize model compound $\mathbf{2 5}$ that was synthesized within nine steps (Scheme 3). For the synthesis of $\mathbf{2 5}$, we started from the known limonene oxide-derived diol 20 [24] that was hydrogenated, oxidized, and silylated at the tertiary alcohol moiety (81\%). Reaction of deprotonated 21 with ethyl cyanoformate afforded cyanohydrin 22 by attack of liberated cyanide at the carbonyl carbon following the ethoxycarbonylation. The ${ }^{3} J_{\mathrm{HH}}$ coupling constant proved that the isopropyl and ethoxycarbonyl groups both assume an equatorial position in a chair conformation.

We were not able to obtain an X-ray analysis of cyanohydrin 22, but of one diastereomer (30) of an analog where the OTBS was replaced by a methoxy group (Scheme 4, obtained by ethoxycarbonylation of 28) [25]. In agreement with the NMR data, cyanohydrin $\mathbf{3 0}$ adopts a chair conformation in the crystal. The ${ }^{1} \mathrm{H}$ NMR spectra of diastereomers 29 and $\mathbf{3 0}$ differ characteristically regarding the chemical shift of the hydroxy proton which appeared as a sharp signal at $5.25 \mathrm{ppm}\left(\mathrm{CDCl}_{3}\right)$ for $\mathbf{2 9}$ and as a broad peak at $3.00 \mathrm{ppm}$ for $\mathbf{3 0}$. This can be explained by the presence of an intramolecular hydrogen bond that is possible only in the case of 29. Since the ${ }^{1} \mathrm{H}$ NMR spectrum of cyanohydrin 22 exhibits a sharp hydroxy peak at 5.29 ppm, we derive the relative configuration shown in Scheme 4.

From cyanohydrin $22 \mathrm{HCN}$ was eliminated by treatment with diluted $\mathrm{NaOH}$ (100\%, Scheme 3). The resulting ketone $\mathbf{2 3}$ reacted with lithiated alkyne $\mathbf{1 2}$ affording diastereomerically pure tertiary alcohol $\mathbf{2 4}$ (63\%) that showed a broad hydroxy signal in the ${ }^{1} \mathrm{H}$ NMR spectrum at $2.61 \mathrm{ppm}$. This indicates that the alkynyl side chain had been introduced from the same side as the ethoxycarbonyl group. By conversion of the ester to an aldehyde group and deprotection we obtained the subject of study, the putative cyclization precursor 25 (71\%). In an orienting reaction, treatment of $\mathbf{2 5}$ with $\mathrm{TiCl}_{4} / \mathrm{Zn}$ did not lead to pinacol cyclization and we have evidence that the aldehyde group stayed in place and the keto group had been reduced. Installation of a TMS group at the tertiary alcohol moiety of $\mathbf{2 5}$ (TMSOTf, 2,6-lutidine) formed 26, which was simply reduced at the keto function on reaction with $\mathrm{TiCl}_{4} / \mathrm{Zn}$ /pyridine (27, Scheme 3) without cyclization. As before, the aldehyde had stayed in place. Interestingly, treatment of $\mathbf{2 5}$ with samarium diiodide afforded the primary alcohol and left the keto group unchanged. Still, no cyclization took place.

One could think that endocyclic elimination of water from $\mathbf{2 4}$ to the $\alpha, \beta$-unsaturated ester would afford a cyclohexene system that would regain the ability of undergoing pinacol cyclization, because the bridge of the [8.4.0] system would become a double bond. However, standard protocols $\left(\mathrm{MsCl} / \mathrm{Et}_{3} \mathrm{~N}\right.$ or $\left.p-\mathrm{TsOH}\right)$ failed. We also synthesized the $(E)$-isomer of 24, compound $\mathbf{3 1}$, via Sonogashira coupling with the $(E)$-isomer [11] of 12. Chlorinated allene $\mathbf{3 2}$ was formed from $\mathbf{3 1}$ as the only product on treatment with $\mathrm{SOCl}_{2}$ /pyridine, presumably after chlorosulfonation, followed by chlorine transfer and loss of $\mathrm{SO}_{2}$ (Scheme 5). There is precedence that elimination towards the cyclohexene can be a competing process [26]. The configuration of the allene moieties could not be elucidated. 


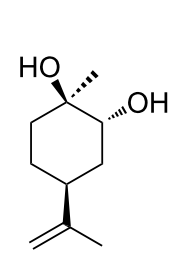

20

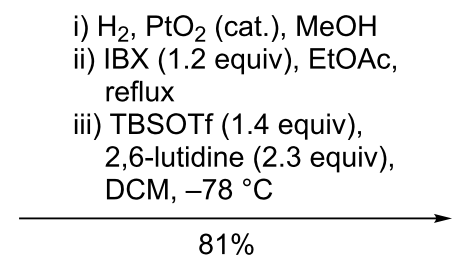

ii) $\mathrm{BX}(1.2$ equiv), EtOAc

2,6-lutidine (2.3 equiv)

$81 \%$
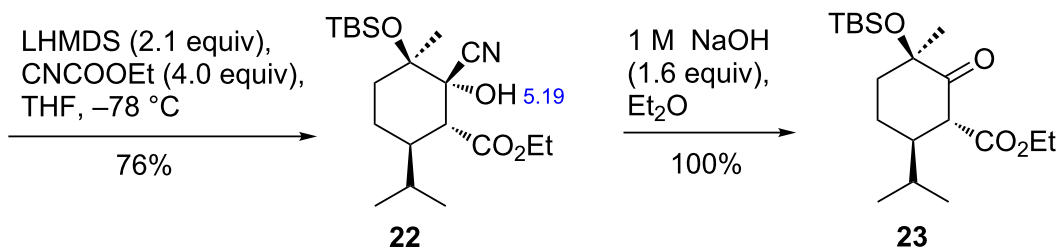

23

(i) 12, $n$-BuLi (1.1 equiv), THF, $-25^{\circ} \mathrm{C}$

(ii) 23 ( 1.2 equiv), $\mathrm{THF},-78^{\circ} \mathrm{C}$

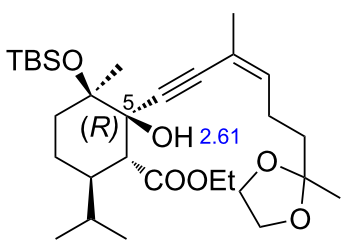

24
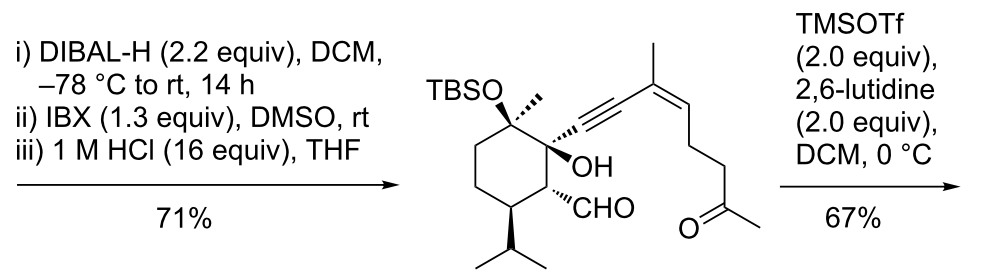

25

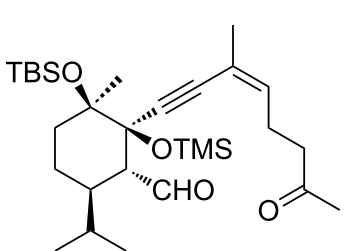

26

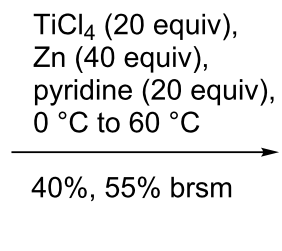

$\mathrm{Zn}$ (40 equiv), pyridine (20 equiv), $0^{\circ} \mathrm{C}$ to $60{ }^{\circ} \mathrm{C}$

$40 \%, 55 \%$ brsm

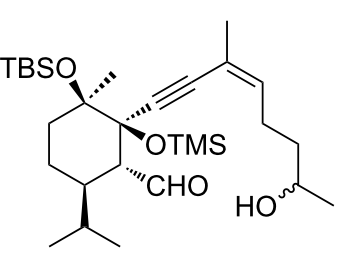

27

Scheme 3: Assembly of the envisaged cyclization precursor 27.

Interestingly, treatment of $\mathbf{3 1}$ with $\mathrm{Tf}_{2} \mathrm{O}$ /pyridine afforded allenyl triflone 34, with ${ }^{13} \mathrm{C}$ NMR signals of the allene center and the triflyl-substituted carbon at $\delta 203.7$ and $113.5 \mathrm{ppm}$, respectively. The sequence probably commences with pyridineassisted conversion of propargylic alcohol $\mathbf{3 1}$ to the propargyl triflate, which looses triflate, forming propargyl cation $\mathbf{3 3}$. Since a triflone is formed rather than a triflate, reduction of the incoming nucleophile must have taken place, probably before incorporation. Corey and Tian reported the formation of 4-substituted $\mathrm{N}$-triflyldihydropyridine derivatives on reaction of pyridine (4 equiv) with $\mathrm{Tf}_{2} \mathrm{O}$ ( 1.5 equiv) in the presence of aryl nucleophiles that occurred already at $-30{ }^{\circ} \mathrm{C}$ within $30 \mathrm{~min}$. Conversion to the corresponding pyridine derivatives was possible on treatment with $\mathrm{KO} t-\mathrm{Bu}$ at $-23{ }^{\circ} \mathrm{C}$, presumably with formation of potassium triflinate [27]. In our case, pyridine was used as solvent and the reaction mixture was heated up to $70{ }^{\circ} \mathrm{C}$. This could allow pyridine itself taking the double role of nucleophile and base, leading to the formation of pyridinium 
<smiles>CO[C@]1(C)CCC(C(C)C)CC1=O</smiles>

28

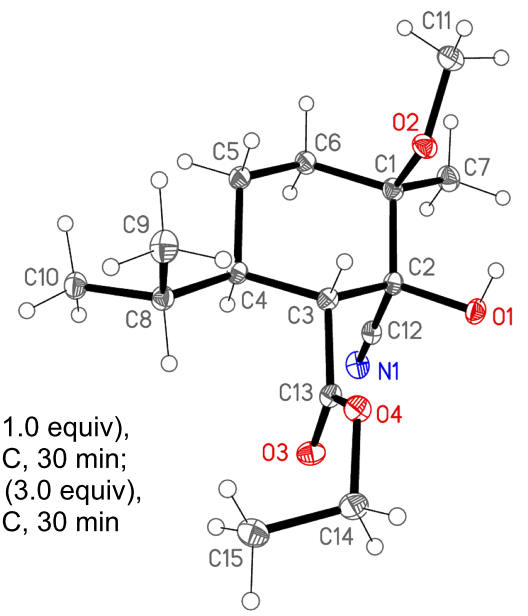

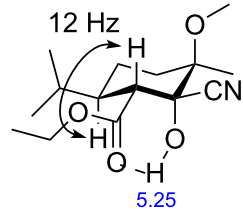

29

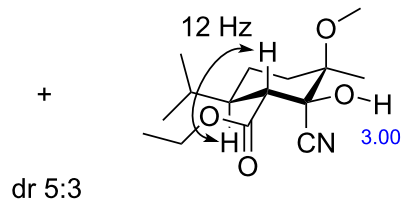

30
Scheme 4: Structure analysis of diastereomeric cyanohydrins 29 and 30.

triflinate. It has also been reported that the triflinate anion can be generated from 2,6-lutidine/ $\mathrm{Tf}_{2} \mathrm{O}$ [28] or $\mathrm{Et}_{3} \mathrm{~N} / \mathrm{Tf}_{2} \mathrm{O}$ [29]. Allenyl triflone 34 could be formed by attack of triflinate as S-nucleophile [30] at the chain carbon of propargyl cation 33. An alternative would be the attack of triflinate as O-nucleo- phile at the cyclohexane carbon, followed by [2,3]-sigmatropic rearrangement [31].

\section{Conclusion}

With the synthesis of the [8.4.0]bicycles $\mathbf{1 8}$ and $\mathbf{1 9}$ that contain a 1,3-cyclohexadiene partial structure, we have made progress towards the synthesis of a small group of bicyclic diterpenoids sharing the eunicellane skeleton. Closure of the ten-membered ring by pinacol cyclization proved to be possible, if the sixmembered ring is either aromatic or a 1,3-cyclohexadiene, but failed for systems with two $\mathrm{sp}^{3}$ centers as bridgeheads. The tenmembered ring of benzene-containing 8 adopts two distinct major conformations in $\mathrm{CDCl}_{3}$, whereas diastereomeric diols 18 and 19 prefer only one, which were elucidated by NOESY spectroscopy. In upcoming studies we will address the synthesis of systems that contain a cyclohexene ring keeping the $\mathrm{sp}^{2}-\mathrm{sp}^{2}$ bridge of the product from the beginning, and of precursors in which one of the centers will be $\mathrm{sp}^{2}$ - and the other $\mathrm{sp}^{3}$ hybridized. Examples of the latter have already been obtained in form of allenes $\mathbf{3 2}$ and $\mathbf{3 4}$ that will now have to be elaborated further.

\section{Supporting Information}

\section{Supporting Information File 1}

Experimental procedures, spectroscopical data, X-ray analysis of 30, and NMR spectra plots.

[https://www.beilstein-journals.org/bjoc/content/ supplementary/1860-5397-14-222-S1.pdf]<smiles>CCOC[C@H]1[C@@H](C(C)C)CC[C@](C)(OC(C)C)[C@@]1(C)C#C/C(C)=C/CCC1(C)OCCO1</smiles>

31

$83 \%$ $\mathrm{SOCl}_{2}$ (10 equiv), pyridine, $0^{\circ} \mathrm{C}$

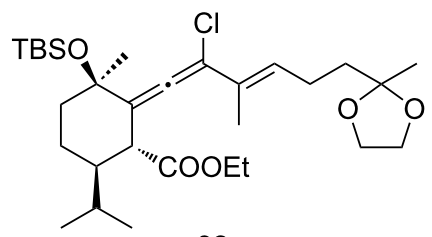

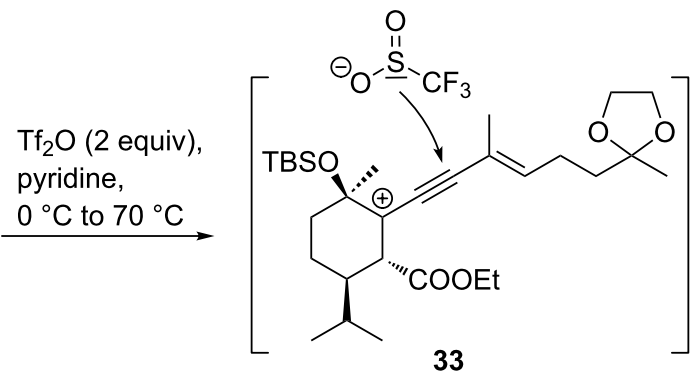

33

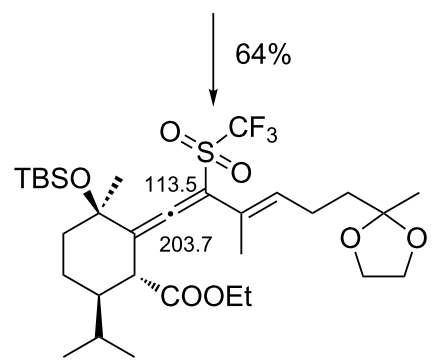

34

Scheme 5: Formation of allenes $\mathbf{3 2}$ and $\mathbf{3 4}$ from sterically crowded propargylic alcohol $\mathbf{3 1}$ 


\section{Acknowledgements}

We thank Merck KGaA (Darmstadt, Germany) for chromatography materials. BASF Group (Ludwigshafen, Germany) and Honeywell Specialty Chemicals Seelze GmbH (Seelze, Germany) are thanked for the donation of solvents.

\section{ORCID ${ }^{\circledR}$ iDs}

Thomas Lindel - https://orcid.org/0000-0002-7551-5266

\section{References}

1. Bloor, S. J.; Schmitz, F. J.; Hossain, M. B.; Van der Helm, D. J. Org. Chem. 1992, 57, 1205-1216. doi:10.1021/jo00030a031

2. Ortega, M. J.; Zubía, E.; Salvá, J. J. Nat. Prod. 1997, 60, 485-487. doi:10.1021/np970026c

3. Chen, B.-W.; Chao, C.-H.; Su, J.-H.; Tsai, C.-W.; Wang, W.-H.; Wen, Z.-H.; Huang, C.-Y.; Sung, P.-J.; Wu, Y.-C.; Sheu, J.-H. Org. Biomol. Chem. 2011, 9, 834-844. doi:10.1039/c0ob00351d

4. Chen, Y.-H.; Tai, C.-Y.; Su, Y.-D.; Chang, Y.-C.; Lu, M.-C.; Weng, C.-F.; Su, J.-H.; Hwang, T.-L.; Wu, Y.-C.; Sung, P.-J. Mar. Drugs 2011, 9, 934-943. doi:10.3390/md9060934

5. Angulo-Preckler, C.; Genta-Jouve, G.; Mahajan, N.; de la Cruz, M.; de Pedro, N.; Reyes, F.; Iken, K.; Avila, C.; Thomas, O. P. J. Nat. Prod. 2016, 79, 1132-1136. doi:10.1021/acs.jnatprod.6b00040

6. Pinto, A. C.; Pizzolatti, M. G.; de A. Epifanio, R.; Frankmölle, W.; Fenical, W. Tetrahedron 1997, 53, 2005-2012. doi:10.1016/s0040-4020(96)01183-0

7. Rinkel, J.; Rabe, P.; Chen, X.; Köllner, T. G.; Chen, F.; Dickschat, J. S. Chem. - Eur. J. 2017, 23, 10501-10505. doi:10.1002/chem.201702704

8. Nicolaou, K. C.; Ohshima, T.; Hosokawa, S.; van Delft, F. L.; Vourloumis, D.; Xu, J. Y.; Pfefferkorn, J.; Kim, S. J. Am. Chem. Soc. 1998, 120, 8674-8680. doi:10.1021/ja9810639

9. Castoldi, D.; Caggiano, L.; Panigada, L.; Sharon, O.; Costa, A. M.; Gennari, C. Angew. Chem. 2005, 117, 594-597. doi:10.1002/ange.200461767 Angew. Chem., Int. Ed. 2005, 44, 588-591. doi:10.1002/anie.200461767

10. Nii, K.; Tagami, K.; Matsuoka, K.; Munakata, T.; Ooi, T.; Kusumi, T. Org. Lett. 2006, 8, 2957-2960. doi:10.1021/ol0608404

11. Al Batal, M.; Jones, P. G.; Lindel, T. Eur. J. Org. Chem. 2013, 2533-2536. doi:10.1002/ejoc.201300178

12. Kato, N.; Kataoka, H.; Ohbuchi, S.; Tanaka, S.; Takeshita, H. J. Chem. Soc., Chem. Commun. 1988, 354-356. doi:10.1039/c39880000354

13. Swindell, C. S.; Fan, W. J. Org. Chem. 1996, 61, 1109-1118. doi:10.1021/j09519367

14. Yamato, T.; Fujita, K.; Okuyama, K.-i.; Tsuzuki, H. New J. Chem. 2000, 24, 221-228. doi:10.1039/b001145m

15. Sergeeva, E. V.; Rozenberg, V. I.; Antonov, D. Y.; Vorontsov, E. V.; Starikova, Z. A.; Fedyanin, I. V.; Hopf, H. Chem. - Eur. J. 2005, 11, 6944-6961. doi:10.1002/chem.200500413

16. Saisyo, T.; Shiino, M.; Shimizu, T.; Paudel, A.; Yamato, T. J. Chem. Res. 2008, 479-483. doi:10.3184/030823408×338701

17. Castagnolo, D.; Contemori, L.; Maccari, G.; Avramova, S. I.; Neri, A.; Sgaragli, G.; Botta, M. ACS Med. Chem. Lett. 2010, 1, 416-421. doi:10.1021/ml100118k

18. Nicolaou, K. C.; Yang, Z.; Liu, J.-J.; Nantermet, P. G.; Claiborne, C. F.; Renaud, J.; Guy, R. K.; Shibayama, K. J. Am. Chem. Soc. 1995, 117, 645-652. doi:10.1021/ja00107a008
19. Ferri, F.; Brückner, R.; Herges, R. New J. Chem. 1998, 22, 531-546. doi:10.1039/a709205i

20. Williams, D. R.; Heidebrecht, R. W. J. Am. Chem. Soc. 2003, 125, 1843-1850. doi:10.1021/ja0279803

21. Nicolaou, K. C.; Sorensen, E. J.; Discordia, R.; Hwang, C.-K.; Minto, R. E.; Bharucha, K. N.; Bergman, R. G. Angew. Chem. 1992, 104, 1094-1096. doi:10.1002/ange.19921040838

22. Comanita, B. M.; Heuft, M. A.; Rietveld, T.; Fallis, A. G. Isr. J. Chem. 2000, 40, 241-253. doi:10.1560/7j4f-d8bg-3fqr-e3td

23. McMurry, J. E.; Miller, D. D. J. Am. Chem. Soc. 1983, 105, 1660-1661. doi:10.1021/ja00344a045

24. Blair, M.; Andrews, P. C.; Fraser, B. H.; Forsyth, C. M.; Junk, P. C.; Massi, M.; Tuck, K. L. Synthesis 2007, 1523-1527. doi:10.1055/s-2007-966033

25. Crystallographic Data Centre as supplementary publications no. CCDC-1853640. Copies of the data can be obtained free of charge from http://www.ccdc.cam.ac.uk/data_request/cif.

26. Masters, K.-S.; Flynn, B. L. J. Org. Chem. 2008, 73, 8081-8084. doi:10.1021/jo800682n

27. Corey, E. J.; Tian, Y. Org. Lett. 2005, 7, 5535-5537. doi:10.1021/ol052476z

28. Ambrose, M. G.; Binkley, R. W. J. Org. Chem. 1983, 48, 674-677. doi:10.1021/jo00153a011

29. Netscher, T.; Bohrer, P. Tetrahedron Lett. 1996, 37, 8359-8362. doi:10.1016/0040-4039(96)01930-2

30. Hendrickson, J. B.; Giga, A.; Wareing, J. J. Am. Chem. Soc. 1974, 96, 2275-2276. doi:10.1021/ja00814a061

31. Braverman, S.; Pechenick, T.; Zafrani, Y. Tetrahedron Lett. 2001, 42 1391-1393. doi:10.1016/s0040-4039(00)02255-3

\section{License and Terms}

This is an Open Access article under the terms of the Creative Commons Attribution License (http://creativecommons.org/licenses/by/4.0). Please note that the reuse, redistribution and reproduction in particular requires that the authors and source are credited.

The license is subject to the Beilstein Journal of Organic Chemistry terms and conditions:

(https://www.beilstein-journals.org/bjoc)

The definitive version of this article is the electronic one which can be found at: doi:10.3762/bjoc. 14.222 